\title{
NOVAS PROPOSIÇÕES TEÓRICAS DA FUNÇÃO SOCIAL DA PROPRIEDADE A PARTIR DA EDUCAÇÃO RURAL INCLUSIVA
}

\section{Fabrício Veiga Costa ${ }^{1}$ \\ Frederico Kern Ferreira Barros ${ }^{2}$}

Resumo: Objetiva-se analisar o paradoxo existente entre os investimentos econômicos e sociais no campo, especificamente da educação rural, tendo como parâmetro a discrepância existente entre a qualidade da educação rural em comparação à urbana no Brasil, segundo dados oficiais levantados. Por meio de pesquisas bibliográfica e documental, e a partir da compreensão destes números, das disposições constitucionais e infraconstitucionais correlatas, propõe-se a ampliação de deveres inerentes ao princípio constitucional da função social da propriedade rural, condicionando seu atendimento à necessidade de que os grandes proprietários rurais equilibrem lucro com investimentos sociais em educação.

Palavras-chave: Educação rural inclusiva; Dever constitucional dos grandes proprietários rurais; Ressignificação da função social da propriedade; Equilíbrio variável econômica e social; Desapropriação por interesse social.

\section{NEW THEORETICAL PROPOSITIONS OF THE SOCIAL FUNCTION OF THE PROPERTY FROM INCLUSIVE RURAL EDUCATION}

\begin{abstract}
The objective is to analyze the paradox that exists between economic and social investments in the field, specifically in rural education, taking as a parameter the existing discrepancy between the quality of rural education compared to urban education in Brazil, according to official data collected. Through bibliographic and documentary research, and based on the understanding of these numbers, of the related constitutional and infraconstitutional provisions, it is proposed to expand duties inherent to the constitutional principle of the social function of rural property, conditioning its attendance to the need for large rural landowners balance profit with social investments in education.
\end{abstract}

Keywords: Inclusive rural education; Constitutional duty of large landowners; Redefining the social function of property; Variable economic and social balance; Expropriation for social interest.

\section{Introdução}

\footnotetext{
1 Professor do Programa de Pós-Graduação Stricto Sensu em Proteção dos Direitos Fundamentais da Universidade de Itaúna -UIT-. Doutorado e mestrado em Direito Processual. Pós-doutorado em Educação e Psicologia. E-mail: fvcufu@uol.com.br. Rua da Capela, n. 18, Bairro Dom Bosco, município de Pará de Minas, CEP 35.661.351.

${ }^{2}$ Mestrando em Proteção dos Direitos Fundamentais da Universidade de Itaúna. Procurador Federal - AGU. Email: fredericobarros.adv@gmail.com.
} 
O presente trabalho tem como objetivo geral analisar o paradoxo entre os investimentos econômicos e sociais no campo, notadamente em educação rural, com base na discrepância existente nos dados levantados sobre a qualidade da educação rural em comparação com a urbana no Brasil. A partir da compreensão destes números, propor-se-á uma reflexão sobre a amplitude do feixe de deveres inerentes ao princípio constitucional da função social da propriedade rural e o seu papel na implementação de uma educação rural inclusiva.

A escolha do tema justifica-se por sua relevância teórica na medida em que se busca não apenas revisitar o conceito de função social de propriedade, mas, também, condicionar o seu atendimento à necessidade de que os grandes proprietários rurais equilibrem lucro com investimentos em educação, realizando uma exploração econômica que atenda aos primados da justiça social. O tema também se mostra atual por ser o Brasil um país com forte desigualdade social e regional, em que a educação é um direito subjetivo público ligado ao mínimo existencial, a fim de buscar uma vida digna, além de ser política chave de emancipação e transformação social, a qual deve ser ofertada de forma inclusiva e que atenda às particularidades regionais e locais.

Outrossim, a temática tem indiscutível relevância prática, dada a necessidade de se buscar alternativas à secundarização histórica da política voltada ao ensino rural, a partir do envolvimento e participação da iniciativa privada, por serem os maiores beneficiários da exploração do trabalho do homem do campo. Busca-se, assim, frear o ciclo vicioso e pernicioso que acentua as desigualdades regionais e perpetua a pobreza no meio rural.

O presente artigo foi desenvolvido em quatro capítulos. No primeiro serão apresentados dados e estatísticas comparativas entre a qualidade do ensino nos meios urbanos e rural, enquanto paralelamente se demonstra a força econômica do agronegócio e da exploração da atividade rural. No segundo capítulo aprofundar-se-á nos cenários opostos que compõem a realidade brasileira, promovendo uma análise comparativa entre investimentos econômicos no campo em contraposição aos investimentos sociais em educação, problematizando-se a legislação regente, oportunidade em que será delineada a perguntaproblema deste artigo.

No terceiro capítulo será resgatada a história constitucional do princípio da função social da propriedade, desde a primeira Constituição Brasileira até a consagração vigente na Constituição Federal de 1988. No quarto e último capítulo serão abordados alguns pontos da 
educação rural brasileira e o seu contexto social, propondo novas reflexões sobre o conteúdo do princípio da função social da propriedade. O referido capítulo conta com um subitem no qual será proposta a aplicação de sanções e coerções previstas no ordenamento jurídico para efetivação desta visão interpretativa que se apresenta.

Os dados obtidos e retratados nesta pesquisa refletem dois cenários diametralmente opostos: de um lado, a educação na zona rural tem apresentado índices de qualidade muito inferiores em relação ao ensino urbano, assim como na taxa de analfabetismo das crianças e jovens em idade escolar. Do outro lado, tem-se o agronegócio, o qual tem se apresentado como o setor mais pujante da economia brasileira, com estatísticas positivas de crescimento e investimento massivo em tecnologia e pesquisas científicas. Diante desses dois cenários antagônicos, delimitou-se o tema a partir da seguinte pergunta-problema: Se o agronegócio tem se mostrado como o motor econômico do país, como fazer para que tais índices positivos possam irradiar para outras áreas além da econômica, como a educação rural inclusiva?

No que tange à metodologia, utilizou-se a pesquisa bibliográfica e documental, por meio de consulta a livros, artigos científicos, revistas estratificadas, levantamento de dados produzidos por órgãos governamentais e entidades representantes da sociedade civil. Por meio da análise destes dados, estudos comparativos e interpretativos foi possível propor reflexões teóricas relativas ao objeto da pesquisa. A utilização do método dedutivo possibilitou trabalhar duas concepções gerais relativas à educação no Brasil e à interpretação do princípio da função social da propriedade, ponto de partida para a delimitação do tema problema, o que permitiu construir perspectivas centradas no ensino no meio rural a partir de novas reflexões sobre o feixe de deveres que compõem a função social da propriedade.

\section{Radiografia da educação brasileira nas zonas urbanas e rurais}

O Brasil é um país marcado por uma histórica desigualdade social, figurando na $79^{\mathrm{a}}$ posição na lista de países classificados no Índice de Desenvolvimento Humano (IDH) em um ranking de 189 países, de acordo com o Relatório divulgado pela Programa das Nações Unidas para o Desenvolvimento Humano (PNUD), ficando atrás do Chile, Argentina e Uruguai (ONU, 2020). À primeira vista, pode-se pensar que estar praticamente no meio da tabela não seria tão ruim. Contudo, um olhar mais atento demonstra que o Brasil é um dos países mais desiguais do mundo se comparado a alguns países do continente Africano e do Oriente Médio. 
Cabe registrar que o IDH fundamenta seus índices em três dimensões: renda, saúde e educação; assim, pode-se afirmar inicialmente uma das causas motivadoras desta desigualdade é a baixa qualidade da educação brasileira. Portanto, apesar da desigualdade social não se restringir a apenas uma causa motivadora, se tratando de um problema multifatorial com diversas ramificações, ater-se-á no presente artigo ao fator educação, por se tratar do tema central, a partir do qual este se desenvolve e abre espaço para outros panoramas. A Organização das Nações Unidas para a Educação, a Ciência e a Cultura (UNESCO), em seu Relatório de Monitoramento Global da Educação (UNESCO, 2020), traz em seu prefácio um destaque importante acerca da capacidade de transformação social pela educação:

A educação realiza uma contribuição essencial na construção de sociedades inclusivas e democráticas, nas quais diferentes opiniões podem ser manifestadas livremente e nas quais uma ampla variedade de vozes pode ser ouvida, na busca da coesão social e na celebração da diversidade (UNESCO, 2020, p. 7).

A educação é capaz não apenas de transformar realidades, o que, indubitavelmente, já seria motivo suficiente para sua priorização como política pública permanente e primordial de qualquer Estado. Mais do que isso, a educação se apresenta como um dos pilares de sustentação do regime democrático, por meio da construção de uma sociedade plural, livre, justa, solidária, cuja cidadania, o pleno desenvolvimento da pessoa humana e a preparação para o mercado de trabalho serão construídos a partir do pensamento crítico. O relatório ainda traz um alerta quanto à necessidade de uma educação que se mostre e aperfeiçoe de forma inclusiva:

\footnotetext{
A inclusão na educação significa garantir que todos os estudantes se sintam valorizados e respeitados, e que possam desfrutar de um verdadeiro sentimento de pertencimento. No entanto, muitos obstáculos se colocam no caminho rumo a esse ideal. Discriminação, estereótipos e alienação excluem muitos. Esses mecanismos de exclusão são essencialmente os mesmos, sendo relativos a gênero, local onde vivem, riqueza, deficiência, etnia, língua, migração, deslocamento, orientação sexual, encarceramento, religião ou outras crenças e atitudes (UNESCO, 2020, p.7).
}

Nessa reflexão, para que a educação seja inclusiva, é necessário que o ensino chegue em todos os cantos e locais do país, incluindo-se os mais longínquos espaços, como a zona rural. Entretanto, se de início pensar em homogeneidade seria impossível num país como o Brasil, marcado por inúmeras particularidades sociais, econômicas, culturais e de profunda desigualdade social, além da sua dimensão geográfica, seria plausível ao menos se exigir que o ensino atenda a padrões mínimos de qualidade, indiferente de região geográfica ou do quão 
distante seja a localidade. Infelizmente, na prática, não é o que acontece, especialmente se considerarmos a disparidade entre a qualidade do ensino nas zonas urbanas e rurais.

De acordo com dados da Pesquisa Nacional por Amostra de Domicílios (PNAD) no ano de 2015, a maior parte da população brasileira, 84,72\%, vivia emáreas urbanas; já 15,28\% dos brasileiros viviam em áreas rurais (IBGE, 2020). Apesar de ainda haver uma população considerável de famílias vivendo na zona rural, percebe-se uma disparidade preocupante, seja quanto ao acesso à educação ou mesmo quanto a sua qualidade. Tais afirmações podem ser facilmente comprovadas por meio dos dados coletados e retratados no Índice de Desenvolvimento Humano Municipal Brasileiro, que também traz uma visão específica em relação à educação.

Em comparação com os índices de IDHM urbano e rural, que permite uma visão mais setorial do problema, o IDHM Educação urbano foi de 0,637 , enquanto o rural apresentou menor índice, de 0,441 (IDHM Educação muito baixo) ${ }^{3}$. O Atlas do Desenvolvimento Humano no Brasil mostra também que as taxas de analfabetismo para os estados brasileiros apresentam grande discrepância entre os meios urbano e rural. A taxa de analfabetismo agregada do Brasil em 2010 foi de 9,61\%, porém com 7,54\% de analfabetos no meio urbano e $22,84 \%$ no rural $^{4}$.

Em complementação aos dados extraídos do Atlas de Desenvolvimento Humano, buscou-se enriquecer as estatísticas e o cenário em que se encontra a educação rural no Brasil mediante a utilização de alguns indicadores educacionais levantados pelo Instituto Nacional de Estudos e Pesquisas Educacionais Anísio Teixeira - INEP ${ }^{5}$. Diante dos dados encontrados, verifica-se que nos ensinos fundamental e médio as taxas de distorção para o ano de 2019 são

\footnotetext{
${ }^{3}$ O Atlas do Desenvolvimento Humano no Brasil engloba o Atlas do Desenvolvimento Humano nos Municípios e o Atlas do Desenvolvimento Humano nas Regiões Metropolitanas. O Atlas é, uma plataforma de consulta ao Índice de Desenvolvimento Humano Municipal (IDHM) de 5.565 municípios brasileiros, 27 Unidades da Federação (UF), 21 Regiões Metropolitanas (RM) e 3 Regiões Integradas de Desenvolvimento (RIDE) e suas respectivas Unidades de Desenvolvimento Humano (UDH). Disponível em http://atlasbrasil.org.br/2013/pt/o_atlas/o_atlas_/. Acesso em 20 ago. 2020.

${ }^{4}$ Para obtenção dos dados relativos à taxa agregada de analfabetos no meio rural e urbano foram consideradas apenas as faixas etárias de 11 a 14 anos e de 15 a 17 anos. Registre-se que se trata de sítio com consulta interativa, de modo que para obtenção das taxas acima devem ser lançados os dados para a devida filtragem. Disponível em sítio http://atlasbrasil.org.br/2013/pt/consulta/. Acesso em 20 ago. 2020.

${ }^{5}$ Segundo sítio do INEP-MEC (http://portal.inep.gov.br/web/guest/indicadores-educacionais), os indicadores educacionais atribuem valor estatístico à qualidade do ensino, atendo-se não somente ao desempenho dos alunos, mas também ao contexto econômico e social em que as escolas estão inseridas. Eles são úteis principalmente para o monitoramento dos sistemas educacionais, considerando o acesso, a permanência e a aprendizagem de todos os alunos. Dessa forma, contribuem para a criação de políticas públicas voltadas para a melhoria da qualidade da educação e dos serviços oferecidos à sociedade pela escola.
} 
respectivamente de $14,9 \%$ e $25,6 \%$ no meio urbano e de $24,9 \%$ e $38 \%$ no rural, segundo o mais recente Censo Escolar. A taxa de distorção idade-série busca retratar o percentual de alunos, em cada série, que têm idade acima da esperada para o ano em que estão matriculados (INEP, 2020).

Outro dado relevante é a média de horas-aula diária no decorrer do ano de 2019, a qual demonstra a quantidade de horas que cada aluno permanece em sala de aula aprendendo e integrando-se socialmente. Na educação infantil, ensino fundamental e ensino médio, para o meio urbano tem-se uma média diária de horas-aulas na seguinte ordem: de $6,1 \%, 4,6 \%$ e 5,2 $\%$, e no meio rural para os mesmos níveis escolares de apenas 4,7\%, 4,5\% e 5,1\%. Para além de um olhar que foca apenas o aspecto do aluno, é profícuo trazer dados sobre a qualidade do corpo docente, o que irrefutavelmente reflete na qualidade de ensino e no nível de aprendizagem do educando. Deste modo, tem-se os seguintes números relativos ao percentual de funções docentes com curso superior no Brasil: no ensino fundamental e médio, o meio urbano representa um quantitativo respectivamente no percentual de 91,4\% e 97,5\%, enquanto o rural representa apenas $76 \%$ no ensino fundamental e $92,5 \%$ no ensino médio (INEP, 2020) ${ }^{6}$. A partir desses dados é fácil constatar que a educação brasileira não tem se expandido de forma inclusiva e abrangente de maneira a absorver os diferentes Brasis existente dentro deste Brasil maior e cheio de diversidade, excluindo a zona rural deste processo de pertencimento e transformação social por meio da educação. É notório que se a melhoria da qualidade do ensino no Brasil, de uma forma geral, tem se mostrado lenta e aquém do esperado e desejável, no meio rural o panorama é alarmante, chegando a ser excludente, alimentando um sistema social vicioso que mantém um ciclo de pobreza e desigualdade social.

Em outra vertente, o campo tem se apresentado como o motor econômico do país por meio do agronegócio, batendo recorde de safras e superávit na balança comercial ano após ano. No ano de 2019 o agronegócio representou 21,4\% do Produto Interno Bruto brasileiro, com um crescimento de $3,81 \%$ em relação a 2018, com taxas de crescimento bem superiores

\footnotetext{
${ }^{6}$ Percebe-se uma subnotificação acerca de dados oficiais sobre o ensino no meio rural, as estatísticas e dados disponíveis são inferiores e menos abrangentes do que aqueles inerente a educação urbana. A referida percepção decorre da resposta a solicitação de informações realizada ao sítio fala.br - Plataforma Integrada de Ouvidoria e Acesso à Informação, de dados relativos ao ensino rural, registrado sob o número 23546.044625/2020-73. Disponível

em: https://falabr.cgu.gov.br/publico/Manifestacao/DetalharManifestacaoSolicitante?id=pCaUkV7\%2bYPc\%3d\&cac $=\mathrm{MB} 2 \mathrm{q} \% 2 \mathrm{fcR} 402 \mathrm{AvuGeMbZbS2A} \% 3 \mathrm{~d} \% 3 \mathrm{~d}$. Acesso em 19 set. 2020.
} 
ao PIB brasileiro (CNA, 2020). Somente no plano safra de 2018/2019 foram destinados pelo Governo Federal recursos na ordem de R \$ 194,37 bilhões, com a finalidade de financiar o agronegócio (BRASIL, 2019), valor consideravelmente superior ao orçamento do Ministério da Educação previsto para o ano de 2019 na ordem de R\$ 118,40 bilhões (CGU, 2020). Entretanto, apesar de todo o vigor econômico do campo, este não tem irradiado para o social com a mesma proporção e velocidade, notadamente quando se depara com os dados relativos à educação na zona rural no Brasil ora expostos de forma crítica na presente pesquisa.

\section{Brasil paralelo: dicotomia entre investimentos econômicos no campo (agronegócio) $x$ investimentos sociais na educação.}

A partir da análise dos dados mostrados acima depara-se com dois cenários diametralmente opostos: de um lado, a educação na zona rural tem apresentado índices de qualidade muito inferiores em relação ao ensino urbano, assim como na taxa de analfabetismo das crianças e jovens em idade escolar. Do outro lado, tem-se o agronegócio, o qual se apresenta como o setor desenvolvimentista da economia brasileira, com estatísticas positivas de crescimento e investimento massivo em tecnologia e pesquisas científicas. Com base nesses dois cenários opostos, chega-se ao paradoxal questionamento que se traduz na pergunta-problema deste artigo: Se o agronegócio tem se mostrado como o motor econômico do país, como fazer para que tais índices positivos possam irradiar para outras áreas além da econômica, como a educação rural?

A educação é um direito social e um dever do Estado e da família; será promovida e incentivada com a colaboração da sociedade, consoante disposição constitucional insculpida no artigo 205, caput, devendo o ensino ser ministrado com base no princípio da igualdade de condições de acesso e permanência na escola e mediante a garantia de padrão de qualidade (art.6, caput cumulado com artigo 206, Incisos I e VII, CF/88). O processo educacional deve ser dialogicamente construído pela sociedade, família e Estado, objetivando-se constitucionalmente o pleno desenvolvimento da pessoa humana, preparação para o mercado do trabalho e formação cidadã, ressaltando-se que tais premissas jurídico-constitucionais se funda no interesse estatal de construção efetiva do Estado Democrático de Direito.

A Lei de Diretrizes Básicas da Educação, de nº 9.394/1996 (BRASIL, 1996), insculpiu como primeiro princípio a ser seguido que o ensino se desenvolva em um ambiente de igualdade de condições para o acesso e permanência na escola. Além deste, estabelece 
outros princípios relevantes, tais como a coexistência de instituições públicas e privadas de ensino, a garantia de padrão de qualidade e a vinculação entre a educação escolar, o trabalho e as práticas sociais, os quais estão previstos no artigo $3^{\circ}$, Incisos I, V, IX, XI LDB (Lei de Diretrizes e Base para a Educação Nacional). A referida lei dedica apenas um único dispositivo ao ensino rural, tratando a questão de forma bem superficial e insuficiente, o que reflete a secundarização histórica da política educacional voltada para o campo (art. 28, LDB, $1996)^{7}$.

O descaso deliberado com a educação rural, face a ausência de legislação específica sobre o tema, obriga o intérprete a socorrer-se de outros diplomas que permeiam a questão do trabalhador rural, e acidentalmente tratam da educação rural. O Estatuto da Terra prevê em seu artigo 73, caput, que a educação através de estabelecimentos agrícolas de orientação profissional será um dos meios atinentes à política de desenvolvimento rural (art.73, Lei $\mathrm{n}^{\circ}$ 4.504, de 30 de novembro de 1964). Em complementação, o parágrafo $§ 1^{\circ}$ prevê que os meios enumerados no caput serão utilizados para dar plena capacitação ao agricultor e sua família, visando especialmente ao preparo educacional, à formação empresarial e técnico profissional. Por sua vez, o art.16 da Lei $\mathrm{n}^{\circ} .5 .889 / 73$ (BRASIL, 1973), que regulamenta o trabalho no campo, prevê a obrigatoriedade de que o empregador rural que mantenha a seu serviço mais de cinquenta famílias de trabalhadores de qualquer natureza, possua e conserve em funcionamento escola primária, inteiramente gratuita, para os filhos destes.

Em face deste contexto, cabe registrar que em 2002 dos 353 estabelecimentos privados que oferecem o ensino fundamental no meio rural de $1^{\mathrm{a}}$ a $4^{\mathrm{a}}$ série e que atendem 18.079 alunos, $31 \%$ eram mantidos por empresas (BOF; SAMPAIO; OLIVEIRA, 2006). É notório que a obrigação dos proprietários rurais não se encerra com a mera construção de escolas; pelo contrário, tem um escopo mais abrangente à luz das disposições normativas mencionadas acima, assim como dos princípios constitucionais que regem o ensino, dentre eles o que prevê a obrigatoriedade de garantia de um padrão mínimo de qualidade. Nesse

\footnotetext{
${ }^{7}$ Art. 28. Na oferta de educação básica para a população rural, os sistemas de ensino promoverão as adaptações necessárias à sua adequação às peculiaridades da vida rural e de cada região, especialmente: I - conteúdos curriculares e metodologias apropriadas às reais necessidades e interesses dos alunos da zona rural; II organização escolar própria, incluindo adequação do calendário escolar às fases do ciclo agrícola e às condições climáticas; III - adequação à natureza do trabalho na zona rural. Parágrafo único. O fechamento de escolas do campo, indígenas e quilombolas será precedido de manifestação do órgão normativo do respectivo sistema de ensino, que considerará a justificativa apresentada pela Secretaria de Educação, a análise do diagnóstico do impacto da ação e a manifestação da comunidade escolar. (Incluído pela Lei no 12.960, de 2014).
} 
sentido, a partir de uma interpretação sistemática das disposições constitucionais e infraconstitucionais supramencionadas, é possível afirmar que o setor privado tem o dever constitucional de auxiliar na política estatal de implementação de um ensino inclusivo, emancipatório e que atenda a padrões mínimos de qualidade, especialmente na zona rural.

A colaboração da sociedade à qual o texto constitucional se refere em seu art.205, caput, significa atuação ativa e permanente das empresas e do agronegócio, especialmente naquelas localidades onde o Estado não se faz presente ou que possui maiores de dificuldades para chegar. Aliás, conforme já demonstrado alhures, essa participação de empresas subsidiando escolas e o ensino no meio rural já vem sendo feita por algumas empresas e proprietários rurais, contudo, não ocorre de forma eficiente e proporcional aos investimentos econômicos ocorridos no âmbito do agronegócio no Brasil. Com base nessa reflexão, não seria leviano entender que esse dever constitucional também deriva do atendimento à função social da propriedade, que estabelece, entre outros requisitos, que a exploração deve favorecer o bem-estar dos trabalhadores (art.186, IV CF/88), destacando-se que esse bem-estar mencionado pelo legislador constituinte obrigatoriamente deverá englobar o acesso livre e igualitário à educação.

Ademais, sendo a função social princípio orientador da atividade econômica em nível constitucional, à luz do disposto no art.170, III, da CF/88, a exploração da terra deve se dar em conformidade com os ditames da justiça social. Isto por que, "justiça social não simboliza apenas superação das injustiças na repartição do proveito econômico, mas meio e fim de qualquer política econômica capitalista" (GRAU, 1997, p.224). Em outras palavras, significa ter o mesmo olhar e tratamento conferido ao social àquele reservado à parte econômica, de forma a manter um equilíbrio entre interesse público e privado. Assim, justiça social deve ser compreendida constitucionalmente como o pleno e gozo efetivo, igualitário e cidadão dos direitos fundamentais previstos no plano constituinte e instituinte. Para melhor compreensão do conteúdo e amplitude do princípio da função social da propriedade rural e de que forma este se conecta umbilicalmente com a educação rural, faz-se necessário, antes de mais nada, revisitar a evolução deste princípio e sua inserção no contexto do ordenamento jurídico brasileiro.

\section{Apontamentos jurídico-constitucionais do princípio da função social da propriedade.}


O estudo crítico e a ressignificação do direito de propriedade a partir do princípio da função social no ordenamento jurídico brasileiro ocorreram de forma, no mínimo, cambaleante e gradual, com avanços e retrocessos, até se chegar ao entendimento consagrado na Constituição da República de 1988. A primeira Constituição Brasileira de 1824 (BRASIL, 1824), promulgada quando o Brasil ainda era um Império, não fez qualquer menção à função social da propriedade, momento histórico em que ainda vigiam os resquícios e problemas fundiários relativos aos antigos regimes de sesmarias e terras devolutas. Ademais, é importante ressaltar que nesse período da história brasileira vigorava-se o Estado Liberal, fundado nas máximas jurídicas do direito privado, além de ser focado na proteção dos direitos das pessoas individualmente (relações jurídicas entre particulares), fato esse que justifica a omissão do legislador constituinte em abordar a questão referente à função social da propriedade privada.

A Constituição Republicana de 1891(BRASIL, 1891), sob influência do paradigma liberal, manteve basicamente o conceito da Constituição Imperial, consoante dispunha o artigo 72, §17 (AZEVEDO, 2019, p. 261):

Art.72 - A Constituição assegura a brasileiros e estrangeiros residentes no país a inviolabilidade dos direitos concernentes à liberdade, à segurança individual e à propriedade, nos termos seguintes: [...]. §17. O direito de propriedade mantém-se em toda a sua plenitude, salvo a desapropriação por necessidade, ou utilidade pública, mediante indenização prévia (BRASIL, 1891).

Observa-se um silêncio proposital nas Constituições de 1824 e 1891, marcadas pelo pensamento individualista liberal e burguês, as quais limitaram-se a declarar e garantir o direito de propriedade em toda a sua plenitude, não impondo qualquer limite ao direito de propriedade em geral, com a ressalva da possibilidade de desapropriação por necessidade ou utilidade social (JELINEK, 2006). A Constituição de 1934 (BRASIL, 1934) inova na ordem constitucional ao fazer referência de forma inédita e expressa à atividade do proprietário, prevendo que o direito de propriedade não pode ser exercido contra o interesse social ou coletivo. Apesar de importante previsão constitucional, a novidade é considerada tímida, pois apenas cria um limite negativo ao direito de propriedade. No art. $113^{8}$, contemplou-se previsão

\footnotetext{
${ }^{8}$ Art 113 - A Constituição assegura a brasileiros e a estrangeiros residentes no País a inviolabilidade dos direitos concernentes à liberdade, à subsistência, à segurança individual e à propriedade, nos termos seguintes: [...] $\$ 17$ É garantido o direito de propriedade, que não poderá ser exercido contra o interesse social ou coletivo, na forma que a lei determinar. A desapropriação por necessidade ou utilidade pública far-se-á nos termos da lei, mediante prévia e justa indenização. Em caso de perigo iminente, como guerra ou comoção intestina, poderão as
} 
além da desapropriação por necessidade ou utilidade pública, do usucapião pro labore e da ocupação temporária da propriedade particular (JELINEK, 2006).

Apesar dos primeiros avanços no delineamento do direito de propriedade, a Constituição de 1937 (BRASIL, 1937), editada com espírito autoritário e sob ideais de cunho fascista, significou notório retrocesso, apenas resguardando o direito de propriedade, mas silente quanto ao seu conteúdo, enquadrando a sua definição como matéria de ordem infraconstitucional. Segundo Tepedino e Schreiber (2005), somente com a Constituição de 1946 (BRASIL, 1946), produto de uma postura intervencionista e assistencialista adotada pelo Estado brasileiro, é que se introduziu a funcionalização da propriedade ao interesse social. Para eles, o artigo 147 do texto constitucional foi inspirado e se assemelhava àquele estampado na Constituição de Weimar, considerada o primeiro texto constitucional a consagrar a função social da propriedade como princípio constitucional, o qual influenciou, além do Brasil, outros países.

A Constituição de 1967 (BRASIL, 1967), de certo modo, apenas repetiu o texto da constituição anterior, de 1946, com destaque para a inclusão da função social da propriedade no capítulo da ordem econômica (Art.160, III). Com o fim da ditatura e restabelecimento do ambiente democrático, criou-se o cenário para a elaboração de uma nova constituição, tendo a Constituição Federal de 1988 garantido tratamento amplo e concretizante à função social, fugindo da tradição constitucional anterior, que olhava para a matéria de forma genérica e abstrata, não apenas como direito e garantia individual e princípio da ordem econômica, mas também com um conteúdo mínimo (TEPEDINO; SCHREIBER, 2005).

A partir desse tratamento constitucional, migrou-se de um prisma privatista e agregouse ao direito de propriedade o dever jurídico de agir em vista do interesse coletivo. Ademais, não é despiciendo lembrar que "a função social se torna parte integrante do conteúdo da propriedade privada" (JELINEK, 2006, p. 21). Em outras palavras: "não há, no texto constitucional brasileiro, garantia à propriedade, mas tão somente garantia à propriedade que cumpre sua função social” (TEPEDINO; SCHREIBER, 2005, p. 105). Conforme Jelinek (2006), o princípio da função social da propriedade pode ser resumido em três formas distintas de incidência sobre o direito de propriedade: a) privação de determinadas faculdades; b) obrigação de exercitar determinadas faculdades e c) complexo de condições para o

autoridades competentes usar da propriedade particular até onde o bem público o exija, ressalvado o direito à indenização ulterior (BRASIL, 1934). 
exercício de faculdades atribuídas. Neste artigo interessa a obrigação positiva inerente ao conteúdo do direito de propriedade, na qual se insere um dever jurídico do proprietário de atender a uma prestação positiva, sendo insuficiente a mera abstenção jurídica como forma de observância aos ditames da função social da propriedade.

\section{Educação rural inclusiva e função social da propriedade privada rural.}

A educação rural no Brasil tem se pautado em uma política de exclusão social que ignora as especificidades e a identidade cultural do homem do campo, que relega a segundo plano suas necessidades e o contexto social em que ele se insere, que oferta tratamento nitidamente desigual entre o ensino em meio urbano e rural, e o mais preocupante: não conhece profundamente tal realidade por sequer dispor de dados aprofundados equivalentes aos que subsidiam as estatísticas e permitem diagnóstico relativo à educação urbana.

Não obstante a relevância das questões pedagógicas e seu caráter fundamental para o desenvolvimento do ensino, o que realmente tem o condão de fixar o homem à terra são as condições econômicas e as políticas implementadas para o setor, e não a pedagogia. Se as condições econômicas, mas também sociais, não forem favoráveis à manutenção dos trabalhadores rurais na roça, não há pedagogia que garanta sua permanência (NETO, 2016).

A realidade social descrita não é obra do acaso, mas produto da ação, ou pode-se também dizer da omissão dos homens, que igualmente não se transforma por acaso. Sendo os homens os responsáveis e produtos desta realidade, transformar a realidade opressora é tarefa histórica dos homens. E para que os oprimidos lutem por sua libertação é preciso que tenham consciência crítica da opressão (FREIRE, 1987). Tal libertação preconizada por Paulo Freire somente é possível a partir de uma reinterpretação do princípio da função social da propriedade, a ponto de compreender que o seu conteúdo engloba uma prestação positiva das grandes empresas e proprietários que exerçam atividade econômica mediante exploração da terra. É nesse contexto propositivo que a presente pesquisa objetiva problematizar a relação existente entre os conceitos de função social da propriedade privada rural e o exercício efetivo e igualitário do direito fundamental à educação pelos trabalhadores rurais e demais membros que integram sua família, como é o caso dos filhos.

Deve ser enfatizado que o referido princípio não comporta apenas um não fazer algo em prejuízo de alguma pessoa, mas também de exercê-lo em benefício de outrem, como fonte de comportamento positivo, uma função social ativa (GRAU, 1997). A propriedade tem, na 
verdade, função bivalente na ordem jurídica, seja como direito ou como dever. Nesse contexto, se insere a obrigação de as empresas atribuírem uma função social à propriedade rural e, lado a lado com o Estado, imprimirem esforços por meio de recursos financeiros e humanos para que a educação no campo não seja uma mera política de esquecimento e de manutenção do status quo (situação de opressão), de forma que a exploração da terra favoreça o bem-estar dos trabalhadores, consoante sinaliza o artigo 186, inciso IV, da Constituição Federal.

A referida construção teórica é possível a partir da inteligência do artigo 186, inciso IV, do texto constitucional, que condiciona que a propriedade tenha uma função social, a qual somente é atingida se a exploração favorecer o bem-estar dos trabalhadores. Neste caso, como o inciso IV adota um preceito de conteúdo indeterminado ao se referir ao termo bem-estar, a partir de uma interpretação teleológica é possível compreender que o bem-estar dos trabalhadores somente estará preservado na condição de objetivo da ordem social caso a educação (artigo 193, caput cumulado com 205, caput, ambos da Constituição Federal) seja ofertada ao meio rural pelo menos com os mesmos padrões de qualidade oferecidos ao meio urbano.

Nessa vertente, pretende-se extrair a máxima efetividade da norma constitucional em comento e conectá-la ao seu fim social, consoante determinam tanto a Lei de Introdução às Normas de Direito Brasileiro (BRASIL, 1942), que em seu artigo $5^{\circ}$ aduz que, na aplicação da lei, caberá ao juiz atender aos fins sociais a que ela se dirige e às exigências do bem comum, como o Código Civil (BRASIL, 2002), que estabelece, por meio do artigo 1228 §, que o direito de propriedade deve ser exercido em consonância com as suas finalidades econômicas e sociais. Em reforço à referida proposição teórica, a Constituição Federal consagrou em seu artigo 170, III, a função social da propriedade como princípio orientador da ordem econômica, a qual tem por fim assegurar a todos existência digna. Outrossim, para alcançar tal postulado fundante do ordenamento jurídico constitucional é necessário que a atividade econômica agropecuária se desenvolva segundo os ditames da justiça social e que persiga reduzir as desigualdades regionais e sociais, o que somente ocorrerá no meio rural mediante investimentos direcionados a uma educação que se mostre inclusiva, emancipadora e que respeite as diferenças inerentes ao modo de vida do homem do campo.

Outra concepção que reforça a tese apresentada é construída por meio de um diálogo interdisciplinar entre direito constitucional e direito ambiental, mediante adesão ao princípio 
do poluidor-pagador, que faz uma conexão entre meio ambiente e desenvolvimento econômico, vedando a privatização dos lucros e socialização das perdas. O princípio se funda na teoria econômica de que os custos sociais externos acompanham o processo produtivo, isto é, os custos resultantes dos danos ambientais ou os custos com investimentos sociais em educação devem ser levados em consideração ao se elaborar os custos da produção e, consequentemente, assumi-los (MILARÉ, 2018). A variável social deve compor o planejamento financeiro e estratégico das grandes empresas que exercem atividade rural lucrativa.

Logo, a obtenção de lucros exorbitantes pela exploração do agronegócio e do homem do campo sem uma responsabilidade social por parte do setor privado significa não apenas esvaziar o conteúdo do princípio do poluidor-pagador, mas também dissociar a propriedade privada rural da sua função social. Contudo, estabelecer uma obrigação sem sanção acaba por esvaziar o conteúdo do princípio da função social da propriedade, premiar aquele que descumpre reiteradamente a legislação e punir aqueles que a observam. Portanto, é imperioso avançar na reflexão, analisando as possíveis sanções e meios de coerção em caso de violação por parte do proprietário que não atribui uma função social à sua propriedade.

\subsection{Novas proposições teóricas da função social da propriedade privada a partir de estudos sobre educação rural}

A educação de qualidade é um direito e garantia fundamental, ligado ao mínimo existencial, o qual, diante de um novo olhar sobre o princípio da função social da propriedade, permite compreender que o seu conteúdo engloba uma prestação positiva por parte dos proprietários rurais, especialmente os grandes proprietários rurais ligados ao agronegócio, que devem empreender recursos e esforços para que a educação no campo seja emancipadora, e não excludente. É primordial compreender o papel de transformação social do campo por meio da educação, atribuição que também compete aos grandes proprietários rurais, equilibrando lucro com investimentos em educação, realizando uma exploração econômica que atenda aos primados da justiça social e busque libertar o homem do campo da condição estigmatizante de mero fornecedor de mão de obra barata e desqualificada.

É válido relembrar que não somente o Estado enquanto gestor principal da política educacional tem falhado em seu contento, mas também os grandes empresários rurais, latifundiários e a iniciativa privada como um todo, dado que os números demonstram 
estatísticas alarmantes quanto à qualidade do ensino rural. Desse modo, é importante a formulação de novas reflexões sobre o conteúdo da função social que favoreça o bem-estar dos trabalhadores e familiares, permitindo sua reinserção social a partir da educação.

Cabe ressaltar, todavia, que sem medidas sancionatórias e instrumentos jurídicos de coerção que obriguem os destinatários da norma a cumpri-la, ou que, ao menos, estimule uma atuação social prospectiva dos proprietários rurais, esta teorização será algo de natureza meramente acadêmica, apenas mais um dever constitucional vazio, puramente simbólico e sem capacidade de rompimento de uma estrutura social anacrônica e retrógada. Portanto, é necessário pensar que, em caso de descumprimento, seja possível se chegar até mesmo à desapropriação-sanção do imóvel rural que não cumpra sua função social nos moldes previstos no artigo 184 da Constituição Federal de 1988 e na Lei nº.4.132/1962 (BRASIL, 1962), que em seu artigo $1^{\circ}$ elege a desapropriação por interesse social como instrumento apto a condicionar o uso da propriedade ao bem-estar social.

Um último apontamento que não pode ser esquecido é que a função das empresas não se restringe apenas em investir recursos financeiros na educação rural, uma vez que os problemas e dilemas que envolvem a educação no Brasil não se traduzem apenas em falta de recursos, mas também em como empregá-los e como fazer a gestão adequada destes. Desse modo, a obrigação à qual se incumbe os proprietários rurais não é de natureza exclusivamente financeira, mas também de gestão desses recursos, de modo a obter melhoria nos níveis de avaliações quantitativas e qualitativas do ensino rural. Nesse contexto, a presente pesquisa trouxe à baila o estudo crítico-epistemológico de que toda propriedade rural que pretenda cumprir sua função social deverá desenvolver, além de outras premissas exigidas em lei, o planejamento e a execução de medidas que assegurem o direito de acesso igualitário à educação de qualidade, objetivando-se ressignificar a condição de opressão vivenciada pelos trabalhadores rurais e suas respectivas famílias, haja vista que, dessa forma, tornar-se-á viável o pleno desenvolvimento da pessoa humana, preparação para o mercado de trabalho e exercício da cidadania, premissas essas explicitamente mencionadas no texto da Constituição brasileira de 1988.

\section{Conclusão}

A educação no meio rural tem sido secundarizada historicamente, o que se verifica pela ausência de legislação específica sobre o tema ou diante dos baixos índices de qualidade 
apresentados se comparados com a educação urbana. Ainda mais preocupante é a ausência de estatísticas oficiais que permitam formar uma base de dados, dimensionar os desafios a serem enfrentados e traçar metas e objetivos a serem alcançados.

Dessa forma, faz-se necessário construir novos caminhos que passam por uma ressignificação do conteúdo do princípio da função social da propriedade para extrair, a partir da sua perspectiva ativa, a obrigação dos grandes proprietários rurais equilibrarem lucro com investimentos sociais em educação. Não se pode conceber que a exploração econômica ocorra dissociada de um contexto que promova a justiça social e tenha como objetivo fundamental reduzir as desigualdades sociais e regionais por meio de investimentos em um modelo de educação rural que seja inclusivo, emancipatório e respeite as diferenças inerentes ao modo de vida do homem do campo.

Entretanto, não há obrigação que se torne plenamente exequível sem previsão de sanção, sendo primordial a possibilidade de desapropriação por interesse social daqueles que não atribuírem uma finalidade social à sua propriedade nos mesmos moldes previstos no artigo 184, caput do texto constitucional. Não há dúvidas de que a velocidade das mudanças depende do rompimento de paradigmas interpretativos pré-estabelecidos do texto constitucional, sem o qual não é possível vislumbrar avanços frente a uma tradição histórica de exclusão social, marginalização e de manutenção do status quo que marca negativamente a educação brasileira, em especial o ensino no meio rural.

Nesse contexto propositivo, considerando-se que o setor do agronegócio tem se mostrado como o motor econômico do país, representando significativa parcela do PIB (produto interno bruto), resta clara a necessidade de os proprietários rurais garantirem o efetivo cumprimento integral das premissas condizentes com a função social da propriedade privada rural. Assim, torna-se necessária a institucionalização jurídico-legal e constitucional de parâmetros e vertentes que visam assegurar o cumprimento da função social da propriedade privada rural, mediante o planejamento e a execução de política pública educacional que assegure aos cidadãos que vivem no campo o acesso igualitário e de qualidade às escolas, consideradas espaços que assegurarão o pleno desenvolvimento da pessoa humana, a preparação para o mercado de trabalho e exercício da cidadania. Se eventualmente os proprietários rurais se omitirem quanto a essa obrigação legal e constitucional, propõe-se a desapropriação do imóvel rural como medida coercitivo-punitiva considerada hábil a viabilizar o cumprimento efetivo da função social da propriedade rural por 
meio do acesso à educação, proposta essa que objetiva desconstruir as estruturas sociais que naturalizam a exclusão e a marginalidade das pessoas que vivem no campo.

\section{Referências}

AZEVEDO, Jordano Soares $O$ trabalho escravo na concepção de direito como integridade: em defesa da aplicação imediata da regra do art. 243 da CR/88 / Jordano Soares Azevedo.Belo Horizonte, 2019.261 f. : il..

BOF, Alvana Maria; SAMPAIO, Carlos Eduardo Moreno; OLIVEIRA, Liliane Lucia Nunes de Aranha. Iniciativas de educação para o meio rural nos municípios brasileiros. In: BOF, Alvana Maria (Org.). A educação no Brasil rural. Brasília: Instituto Nacional de Estudos e Pesquisas Educacionais Anísio Teixeira. 2006.

BRASIL. CONSTITUIÇÃO POLÍTICA DO IMPÉRIO DO BRAZIL (DE 25 DE MARÇO DE 1824). Constituição Política do Império do Brasil, elaborada por um Conselho de Estado e outorgada pelo Imperador D. Pedro I, em 25.03.1824. Carta de Lei de 25 de março de 1824. Disponível em:

http://www.planalto.gov.br/ccivil_03/constituicao/constituicao24.htm. Acesso em 01 out. 2020.

BRASIL. Constituição da República dos Estados Unidos do Brasil ( de 24 de fevereiro de 1891). Disponível em: http://www.planalto.gov.br/ccivil_03/constituicao/constituicao91.htm. Acesso em 01 out. 2020.

BRASIL. Constituição da República dos Estados Unidos do Brasil (de 16 de Julho de 1934). Disponível em: http://www.planalto.gov.br/ccivil_03/constituicao/constituicao34.htm. Acesso em 03 out. 2020.

BRASIL. Constituição dos Estados Unidos do Brasil, de 10 de novembro de 1937. Disponível em: http://www.planalto.gov.br/ccivil_03/constituicao/constituicao37.htm. Acesso em 03 out. 2020.

BRASIL. Decreto-Lei $N^{\mathbf{0}}$ 4.657, de 4 de setembro de 1942. Disponível em: http://www.planalto.gov.br/ccivil_03/decreto-lei/del4657compilado.htm. Acesso em 10 out. 2020.

BRASIL. Constituição dos Estados Unidos do Brasil (de 18 de setembro de 1946). Disponível em: http://www.planalto.gov.br/ccivil_03/constituicao/constituicao46.htm. Acesso em 05 out. 2020.

BRASIL. LEI N 4.132, DE 10 DE SETEMBRO DE 1962. Disponível em: http://www.planalto.gov.br/ccivil_03/leis/14132.htm. Acesso em 10 nov. 2020. 
BRASIL. LEI N 4.504, DE 30 DE NOVEMBRO DE 1964. Dispõe sobre o Estatuto da Terra, e dá outras providências. 1964. Disponível em:

http://www.planalto.gov.br/ccivil_03/leis/14504.htm. Acesso em 20 set. 2020.

BRASIL. Constituição da República Federativa do Brasil de 1967. Disponível em: http://www.planalto.gov.br/ccivil_03/constituicao/constituicao67.htm. Acesso em 05 out. 2020.

BRASIL. LEI N 5.889, DE 8 DE JUNHO DE 1973. Estatui normas reguladoras do trabalho rural. 1973. Disponível em: http://www.planalto.gov.br/ccivil_03/leis/15889.htm. Acesso em 22 set. 2020.

BRASIL. Constituição Federal de 1988. Disponível em:

http://www.planalto.gov.br/ccivil_03/constituicao/constituicao.htm. Acesso em 15 set. 2020.

BRASIL. LEI No 9.394, DE 20 DE DEZEMBRO DE 1996. Estabelece as diretrizes e bases da educação nacional. 1996. Disponível em:

http://www.planalto.gov.br/ccivil_03/leis/19394.htm. Acesso em 20 set. 2020.

BRASIL. Lei $\mathbf{N}^{\mathbf{0}} \mathbf{1 0 . 4 0 6}$, de 10 de janeiro de 2002. Disponível em:

http://www.planalto.gov.br/ccivil_03/leis/2002/110406compilada.htm. Acesso em 10 out. 2020

BRASIL. Ministério da Agricultura, Pecuária e Abastecimento. Plano Agrícola e Pecuário 2018 - 2019. 2019. Disponível em:https://www.gov.br/agricultura/pt-br/assuntos/politicaagricola/plano-agricola-e-pecuario. Acesso em 24 ago. 2020.

CNA. PIB do Agronegócio cresce 3,81\% em 2019. 2020. Disponível em:

https://www.cnabrasil.org.br/boletins/pib-do-agronegocio-cresce-3-81-em-2019. Acesso em 22 ago. 2020.

CONTROLADORIA-GERAL DA UNIÃO. Portal da Transparência. Visão geral da distribuição por subárea (subfunção). 2020. Disponível em:http://www.portaltransparencia.gov.br/funcoes/12-educacao?ano=2019. Acesso em 24 ago. 2020.

FREIRE, Paulo. Pedagogia do oprimido. $17^{\text {a }}$ ed. Rio de Janeiro: Paz e Terra, 1987.

GRAU, Eros Roberto. A ordem econômica na Constituição de 1988. 3.ed. São Paulo: Malheiros, 1997.

IBGE. Conheça o Brasil -população rural e urbana. 2020. Disponível em: https://educa.ibge.gov.br/jovens/conheca-o-brasil/populacao/18313-populacao-rural-eurbana.html. Acesso em 27 ago. 2020.

INEP. Indicadores Educacionais. 2020. Disponível em:

http://portal.inep.gov.br/web/guest/indicadores-educacionais. Acesso em 30 ago. 2020 
JELINEK, Rochelle. O princípio da função social da propriedade e sua repercussão sobre o sistema do Código Civil. 2006. Disponível em

https://www.mprs.mp.br/media/areas/urbanistico/arquivos/rochelle.pdf. Acesso em 30 maio 2020 .

MILARÉ, Édis. Princípios fundamentais do direito do ambiente. Revista dos Tribunais, v. 756, p. 53, 1998.

NETO, Luiz Bezerra. L9685 Educação rural no Brasil: do ruralismo pedagógico ao movimento por uma educação do campo. Uberlândia: Navegando Publicações, 2016. p.9.

ORGANIZAÇÃO DAS NAÇÕES UNIDAS. Relatório de Desenvolvimento Humano do PNUD destaca altos índices de desigualdade no Brasil. 2020. Disponível em:

https://nacoesunidas.org/relatorio-de-desenvolvimento-humano-do-pnud-destaca-altosindices-de-desigualdade-no-brasil/. Acesso em 24 ago. 2020.

TEPEDINO, Gustavo; SCHREIBER, Anderson. A garantia da propriedade no direito brasileiro. Revista da Faculdade de Direito de Campos, ano VI, n. 6, jun., 2005. Disponível em http://fdc.br/Arquivos/Mestrado/Revistas/Revista06/Docente/04.pdf. Acesso em 24 ago. 2020.

UNESCO. Relatório de monitoramento global da educação - resumo, 2020: Inclusão e educação: todos, sem exceção. 2020. Disponível em:

https://unesdoc.unesco.org/ark:/48223/pf0000373721_por. Acesso em 25 ago. 2020. 